\title{
EXTRACTION PATTERN OF SOIL MOISTURE IN BARE SOIL, TEA PLANTATION AND SOIL COVERED WITH FOREST SPECIES (Alstonia macrophylla wall)
}

\author{
H M P Peiris and K D N Weerasinghe \\ Faculty of Agriculture, University of Ruhuna
}

The present study conducted at the research farm, Faculty of Agriculture, University of Ruhuna, Mapalana and adjacent site of well established tea plantation from January to July 2003, to assess the moisture extraction patterns under tea (Camellia sinensis L.) and forest speices (Alostonia macrophylla wall) compared to bare soil.

Diviner 2000 is used to assess the soil moisture in different sites. The experiment was conducted in two sites, viz well managed tea plantation and an experimental site where Alstonia macrophylla wall is planted, and bare spots were kept randomly.

The soil under tea was loamy sand with bulk density of $1.3 \mathrm{gcm}^{-3}$ in surface layers which increase with the depth. The soil under forest species was silt loam with a bulk density of $1.4 \mathrm{gcm}^{-3}$ in surface layers. Bulk density of bare soil was highly varied with an average of $1.49 \mathrm{gcm}^{-3}$. A thick laterite layer was found in $40-50 \mathrm{~cm}$ layer in tea soil and $50-60 \mathrm{~cm}$ depth in forest and bare soils. The results revealed that the water holding capacity of tea soil is high by about $16 \%$ compared to that of bare soil and water-holding capacity of forest soil is low by $8 \%$ compared to bare soil.

According to the moisture extraction pattern of soils, somewhat highest retention capacity was in bare land followed by tea soil and then forest soil. The probable reason for this may be high evapotranspiration rate from tea plantation and forest species. The moisture retention of the tea plantation is higher than the forest soil, due to the high evapotranspiration by forest species.

The rate of moisturc depletion is remarkably high in forest soil with an average of $4.8 \mathrm{~mm} /$ day constituting $60 \%$ increment over bare soil evaporation. Soil moisture depletion rate of the soil under tea is about $4.2 \mathrm{~mm} /$ day, which is $40 \%$ higher compared that to the bare soil evaporation. Well-established canopy cover of the tea plantation appeared to be a good barrier to reduce surface evaporation.

Parameters like porosity, soil texture, soil temperature, rainfall, wind speed and root distribution pattern appeared to have an influence on the soil moisture depletion

Proceedings of the Ninth Annual Forestry and Environment Symposium 2003 of the Department of Forestry and Environmental Science, University of Sri Jayewardenepura, Sri Lanka 